\title{
BMJ Open Serum 25-hydroxyvitamin D and risk of cancer in a large community population under investigation for cardiovascular disease: a retrospective cohort study
}

\author{
Jaeun Yang, ${ }^{1}$ Yuan Dong, ${ }^{2}$ Christopher T Naugler, ${ }^{3,4}$ Lawrence de Koning (D) ${ }^{3,4}$
}

To cite: Yang J, Dong Y, Naugler CT, et al. Serum 25-hydroxyvitamin $D$ and risk of cancer in a large community population under investigation for cardiovascular disease: a retrospective cohort study. BMJ Open 2022;12:e056543. doi:10.1136/ bmjopen-2021-056543

- Prepublication history for this paper is available online. To view these files, please visit the journal online (http://dx.doi org/10.1136/bmjopen-2021 056543).

Received 17 August 2021 Accepted 04 January 2022

Check for updates

(c) Author(s) (or their employer(s)) 2022. Re-use permitted under CC BY-NC. No commercial re-use. See rights and permissions. Published by BMJ.

${ }^{1}$ Department of Anesthesiology \& Pain Medicine, University of Alberta Faculty of Medicine \& Dentistry, Edmonton, Alberta, Canada

${ }^{2}$ Community Health Sciences, University of Calgary Cumming School of Medicine, Calgary,

Alberta, Canada

${ }^{3}$ Pathology and Laboratory

Medicine, University of Calgary Cumming School of Medicine,

Calgary, Alberta, Canada

${ }^{4}$ Alberta Precision Laboratories, Calgary, Alberta, Canada

Correspondence to Dr Lawrence de Koning; abldekon@ucalgary.ca

\section{ABSTRACT}

Objectives It remains unclear whether vitamin $D$ status is related to cancer risk. We examined this relationship using laboratory, administrative and survey data.

Design Retrospective cohort study.

Setting All care settings within Calgary, Alberta, Canada and surrounding rural communities.

Participants Patients tested for serum 25-hydroxyvitamin D from 2009 to 2013 without a past cancer diagnosis but with an ECG and body mass index \pm 3 months from testing were included. Age, sex, mean hours of daylight during month of testing were linked to census dissemination area-level indicators of socioeconomic status measured in 2011.

Primary and secondary outcome measures Hospital discharge diagnoses for any cancer, major cancer (colorectal, breast, lung, prostate, skin) and other cancers $>3$ months from testing from 2009 to 2016 . Cox proportional hazard models were used to examine associations with incident cancer after adjusting for potential confounders. Interactions were tested using multiplicative terms.

Results Among 72171 patients, there were 3439 cancer diagnoses over a median of 5.9 years. After adjustment, increasing quartile of serum $25-\mathrm{OH}$ vitamin $\mathrm{D}$ was significantly associated with an increased risk of any cancer and major cancer, however this was completely driven by an increased risk of skin cancer (Q4 vs Q1: $\mathrm{HR}=2.56,95 \% \mathrm{Cl} 1.70$ to 3.86 , $\mathrm{p}$ for linear trend $<0.01$ ). This association was strengthened among individuals residing in communities with higher proportions of noncitizens, recent immigrants, visible (non-white) minorities and those not speaking an official Canadian language (English or French) at home.

Conclusions Higher vitamin D status was associated with a greater risk of skin cancer in a large community population under investigation for cardiovascular disease. This association was likely due to sun exposure and may be modified by community variation in vitamin $D$ supplementation.

\section{INTRODUCTION}

Vitamin D deficiency is defined as a serum 25-OH (hydroxy) vitamin D concentration $<50 \mathrm{nmol} / \mathrm{L},{ }^{1} 2$ which causes reduced absorption of dietary calcium and phosphate
Strengths and limitations of this study

- We assembled a large retrospective cohort study of community patients by linking patient laboratory, national survey and hospital administrative data during a time of high public and medical interest in vitamin $\mathrm{D}$ deficiency, and a commensurately high testing rate at our laboratory for serum 25 -hydroxyvitamin D.

- Linkage allowed us to control for body mass index, a confounder of 25-hydroxyvitamin D-chronic disease relationships and to explore variation in associations according to community-level socioeconomic factors correlated with vitamin D supplement use.

- As our study was restricted to patients who had received an ECG, it may not be generalisable to all patients.

and increases the risk of rickets in children and osteomalacia in adults. ${ }^{1}$ Conversely, vitamin $\mathrm{D}$ toxicity is generally regarded to occur above $250 \mathrm{nmol} / \mathrm{L}$-when symptoms of hypercalcaemia begin to occur. ${ }^{3}$

Vitamin D deficiency is relatively commonespecially in Northern latitudes where people experience less intense solar radiation, spend more time indoors due to cold and experience prolonged periods of darkness during winter. ${ }^{4}$ In Canada, $33 \%$ of residents may be vitamin $\mathrm{D}$ deficient. ${ }^{5}$ As such, there remains significant interest in whether vitamin $\mathrm{D}$ deficiency is related to many common diseasesparticularly cancer.

Meta-analysis of prospective cohort studies suggest that vitamin D deficiency is associated with an increased risk of multiple types of cancer, including all cancers, ${ }^{6}$ colorectal cancer, ${ }^{7}$ bladder cancer ${ }^{8}$ head and neck cancer, ${ }^{9}$ liver cancer $^{10}$ and also death due to cancer. $^{11}$ These associations have been explained by in vitro and in vivo effects of the active form of vitamin $\mathrm{D}\left(1,25 \mathrm{OH}_{2}\right.$ (dihydroxy) vitamin $\mathrm{D}$ ), which promotes 
cellular differentiation, decreases cancer cell growth, stimulates cell death (apoptosis) and reduces angiogenesis. ${ }^{12}$ However, associations may also be explained by the presence of confounding factors that are associated with vitamin $\mathrm{D}$ deficiency and a higher risk of cancer.

For example, adiposity is a sink for and diluent of serum 25-hydroxyvitamin $\mathrm{D}^{13}$ as well as a risk factor for several types of cancer. ${ }^{14}$ As such, adjustment for some measure of adiposity (eg, body mass index (BMI)) is generally recognised as essential to control for bias in epidemiological studies of serum 25-hydroxyvitamin D concentration and cancer risk. ${ }^{1}$ Interestingly, low socioeconomic status (SES), while also a strong a risk factor for vitamin D deficiency ${ }^{15}$ and cancer, ${ }^{16}$ is infrequently controlled forprobably because it is uncommonly measured in epidemiological studies.

Historic uncertainty in the validity of epidemiological findings have thus lead the Institute of Medicine in the USA to indicate that evidence of a relationship between vitamin D status and non-skeletal chronic disease does not meet criteria for establishing cause-and-effect. ${ }^{1}$ However, vitamin $\mathrm{D}$ status could still be a useful and convenient cancer risk marker if its association with cancer risk is independent of other commonly measured factors and is observed in a large population of free-living individuals.

Our objectives were therefore to (i) examine the relationship between serum 25-hydroxyvitamin D (the major circulating form of vitamin D) and risk of cancer in a large community-based population, (ii) adjust for important confounders such as adiposity and SES and (iii) test whether associations are modified by these and other factors.

\section{MATERIALS AND METHODS}

\section{Patient and public involvement statement}

Due to the design of the study and because we did not collect the primary data, we did not involve patients or the public in the design, conduct or reporting of our research.

\section{Population, primary exposure variable and covariates}

We used the Cerner (Kansas City, Missouri, USA) Millennium laboratory information system (LIS) to identify those who had a serum 25-hydroxyvitamin D result with a test date from 8 December 2009 to 1 April 2013. This database contained all laboratory results on patients tested in Calgary, Alberta, Canada (population $~ 1.4$ million) as well as surrounding rural communities. During the time of this study, 25-hydroxyvitamin D testing was available to any ordering physician for any reason-and high test volumes ( 16 000/month) reflected a strong public and medical interest in vitamin D deficiency. For these patients, we retained data only for those who had an ECG because these patients had a self-reported height and weight entered into the LIS to calculate BMI (weight in $\mathrm{kg}$ /(height in $\mathrm{m}^{2}{ }^{2}$ ). We then extracted age, sex and the provincial healthcare number to link to hospital administrative outcome data and postal codes. As vitamin D status is related to sun exposure, we also calculated mean hours of daylight during month of 25-hydroxyvitamin $\mathrm{D}$ testing for each person based on publicly available data. ${ }^{17}$ This was done so that we could adjust for short-term variation in 25-hydroxyvitamin D related to seasonal changes in sun exposure at the time of testing. All serum 25-hydroxyvitamin D tests were performed on the DiaSorin (Saluggia, Italy) Liaison total 25-hydroxyvitamin D automated immunoassay platform, which predominantly detects 25-hydroxyvitamin $\mathrm{D}_{3} \cdot{ }^{18}$ The performance of this assay was validated using guidelines from the Clinical Laboratory Standards Institute (Annapolis Junction, Maryland, USA). Total imprecision was approximately $7 \%$, and results from external proficiency survey samples from the Vitamin D External Quality Assessment Scheme all fell within total allowable error intervals from peer group means $(<20 \mathrm{nmol} / \mathrm{L}$ : $\pm 5 \mathrm{nmol} / \mathrm{L} ; \geq 20 \mathrm{nmol} / \mathrm{L}: \pm 15 \mathrm{nmol} / \mathrm{L})$.

Census dissemination area (CDA)-level SES covariates were obtained from the 2011 Canadian National Household Survey after postal code to CDA conversion. We extracted proportion of CDA residents who were (i) Canadian citizens, (ii) recent immigrants, (iii) visible (non-white) minorities, (iv) those speaking languages other than English and French (official languages of Canada) at home, (v) those having postsecondary education, (vi) those currently employed and the CDA (vii) median household income.

\section{Outcomes}

In-hospital discharge diagnosis and dates were obtained from the Discharge Abstract Database and National Ambulatory Care Reporting System via Alberta Health Services. Incident cancers were defined as the first and most responsible (primary) diagnosis of any cancer (International Classification of Diseases, Tenth Revision codes: C00.x-C97.x), if the patient was discharged alive or died in hospital. We further subdivided 'any cancer' into 'major cancer' ${ }^{19}$ (breast (C50.x), colorectal (C18.xC21.x), lung (C33.x-C34.x), prostate (C61.x) and skin (melanoma: C43.x, non-melanoma: C44.x, C46.x) ${ }^{20}$ specific cancers (breast, colorectal, lung, prostate and skin) and 'other cancer'-defined as 'any cancer' other than 'major cancer'. At the time of analysis, outcome data were available until 31 December 2016.

\section{Data cleaning}

We kept only the first measurement of 25-hydroxyvitamin D to capture historic vitamin D status-which is more likely associated with cancer risk than vitamin D status after supplementation in response to an earlier diagnosis of deficiency. Patients were removed if BMI was measured beyond \pm 3 months from 25-hydroxyvitamin $\mathrm{D}$ testing or was within the top and bottom percentiles. Patients with cancer occurring before or within 3 months of 25-hydroxyvitamin D testing were eliminated to establish temporality and to reduce impact of behaviour changes 

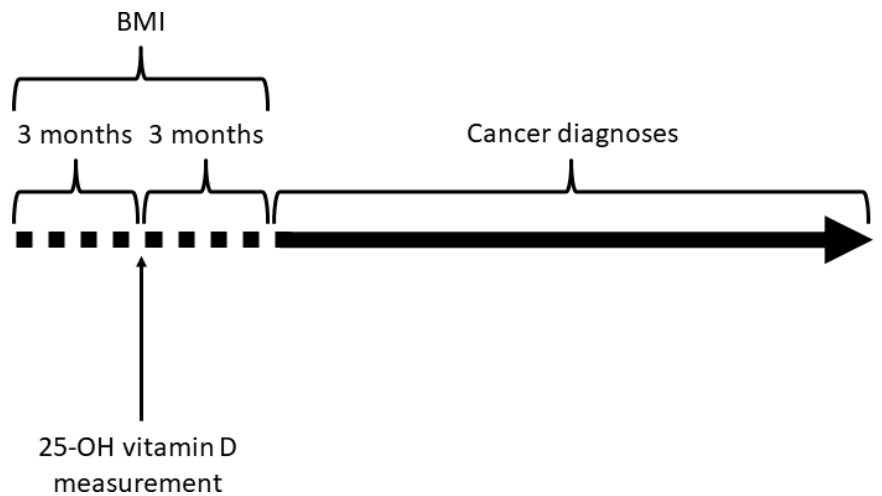

Figure 1 Cohort design. Serum 25-hydroxyvitamin D measurements were made between 2009 and 2013. Census dissemination area-level socioeconomic status covariates were measured in 2011. BMI, body mass index.

or treatment (including supplementation) in response to subclinical or previous disease. The cohort design is shown in figure 1.

\section{Statistical analysis}

Patient characteristics were tabulated according to quartiles of serum 25-hydroxyvitamin D concentration. Linear trends for individual-level data were evaluated using linear and logistic regression. Linear trends for CDA-level SES covariates were evaluated using Poisson regression accounting for clustering of patients by CDA, and variance was calculated using a sandwich estimator.

The relationship between serum 25-hydroxyvitamin D quartile and incident cancer was evaluated using Cox proportional hazard models, with time from 25-hydroxyvitamin D testing to date of cancer diagnosis or censoring (26 December 2016) as follow-up time. For analyses of major and specific cancers, including 'other' cancer, those without the outcome of interest also included those without a diagnosis of any other cancer. We adjusted for age, sex, BMI, mean hours of daylight during month of testing and CDA-level SES covariates in different models. Models adjusted for CDA-level SES covariates accounted for clustering of patients by CDA, and variance was calculated using a sandwich estimator. Because we examined eight separate cancer outcomes, a Bonferroni correction $(0.05 / 8)$ was applied to reduce the nominal significance threshold of $p<0.05$ to $p<0.00625$ in order to minimise type I error. We tested the proportional hazards assumption for each variable by inserting timedependent covariates (eg, 25-hydroxyvitamin D quartilex $\log ($ time $)$ ) into models. If time-dependent covariates reached nominal significance, they were included in all outcome analyses for a given model. ${ }^{21}$

For 25-hydroxyvitamin D-cancer associations that reached the Bonferroni-corrected threshold of significance, we explored possible interactions with all covariates using multiplicative terms in Cox models, and evaluated them using the nominal significance threshold. For convenience, associations were stratified by the median value of these covariates. Finally, we performed

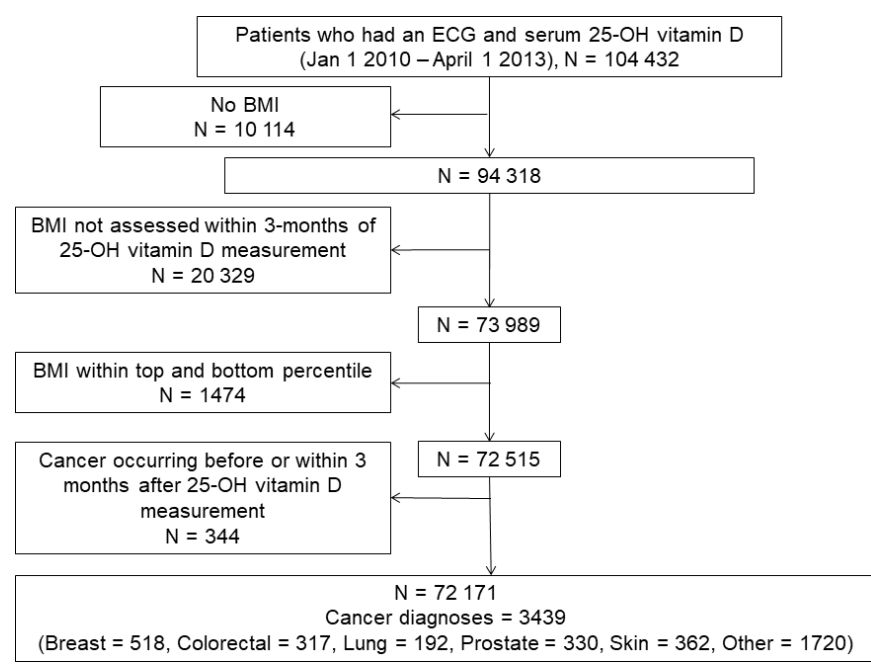

Figure 2 Patient exclusions leading to analysis cohort. BMI, body mass index.

a sensitivity analysis where we excluded participants with a 25-OH vitamin $\mathrm{D}$ concentration of $100 \mathrm{nmol} / \mathrm{L}$ or greater, as these individuals may be more likely to be taking vitamin D supplements. ${ }^{22}$

All data analysis was performed using Statistical Analysis Software (SAS V.9.4).

\section{RESULTS}

After exclusions (figure 2), there were 72171 patients for analysis and 3439 cancer diagnoses (major=1719; breast $=518$, colorectal $=317$, lung $=192$, prostate $=330$ and skin $=362 \quad($ melanoma $=58$, non-melanoma $=304)$; other=1720) over a median of 5.9 years of follow-up. Cancer diagnoses occurred after a median of 3.0 years. There were 2849 CDAs. Approximately $31 \%$ of patients were vitamin D deficient (ie, serum 25-hydroxyvitamin D $<50 \mathrm{nmol} / \mathrm{L}$ ).

Mean age and daylight hours during month of testing significantly increased with serum 25-hydroxyvitamin D quartile whereas proportion of men and mean BMI significantly decreased. We also found that serum 25-hydroxyvitamin $\mathrm{D}$ was lowest when tested in the winter (median $=61 \mathrm{nmol} / \mathrm{L})$ versus the summer (median $=69 \mathrm{nmol} / \mathrm{L})$. Among CDA-level SES covariates, mean proportions of Canadian citizens, those with postsecondary education, employed individuals and the median total household income significantly increased with 25-hydroxyvitamin D quartile whereas the mean proportion of recent immigrants, visible minorities and those using non-official languages at home significantly decreased (table 1). The proportion of all cancer cases increased significantly across 25-hydroxyvitamin D quartile (table 1; $\mathrm{p}$ for trends $<0.001$ ).

Three Cox proportional hazards models were used to further evaluate the association of 25-hydroxyvitamin $\mathrm{D}$ and cancer risk: model 1: adjusted for age, model 2: model 1 adjusted for sex, BMI, mean daylight hours during month of testing and model 3: model 2 adjusted 
Table 1 Patient characteristics by quartile of serum 25-hydroxyvitamin $D$

\section{Serum 25-hydroxyvitamin D quartile}

\begin{tabular}{|c|c|c|c|c|c|}
\hline & & & & & \\
\hline & $\begin{array}{l}\text { Q1 } \\
\text { (10-44 nmol/L) }\end{array}$ & $\begin{array}{l}\text { Q2 } \\
\text { (45-64 nmol/L) }\end{array}$ & $\begin{array}{l}\text { Q3 } \\
\text { (65-87 } \\
\text { nmol/L) }\end{array}$ & $\begin{array}{l}\text { Q4 } \\
(88-658 \mathrm{nmol} / \mathrm{L})\end{array}$ & $\begin{array}{l}P \text { for } \\
\text { linear } \\
\text { trend }\end{array}$ \\
\hline $\mathrm{N}$ & 18053 & 18022 & 18056 & 18040 & \\
\hline $\begin{array}{l}\text { Serum 25-hydroxyvitamin D, median, } \\
\text { mean (SD) }\end{array}$ & $33,31(8.5)$ & $55,55,(5.8)$ & $75,75(6.4)$ & $\begin{array}{l}105,114 \\
(29.6)\end{array}$ & \\
\hline Age, years, mean (SD) & $48(15)$ & $51(15)$ & $54(15)$ & $58(15)$ & $<0.001$ \\
\hline$\%$ Male, (n) & $56.3(10166)$ & $51.4(9261)$ & 45.4 (8199) & 40.1 (7218) & $<0.001$ \\
\hline $\mathrm{BMI}, \mathrm{kg} / \mathrm{m}^{2}$, mean $(\mathrm{SD})$ & $27.4(5.3)$ & $27.3(5.1)$ & $26.9(5.1)$ & $26.1(4.8)$ & $<0.001$ \\
\hline $\begin{array}{l}\text { Daylight hours during month of } \\
\text { testing, mean (SD) }\end{array}$ & $11.9(2.9)$ & $12.2(2.9)$ & $12.4(2.9)$ & $12.5(2.9)$ & $<0.001$ \\
\hline \multicolumn{6}{|c|}{ Census dissemination area-level measures of socioeconomic status } \\
\hline Canadian citizens, mean \% (SD) & $88.1(10.1)$ & $89.8(8.9)$ & $91.0(8.1)$ & $91.9(7.5)$ & $<0.001$ \\
\hline Recent immigrants, mean \% (SD) & $33.4(16.8)$ & $30.0(16.2)$ & $27.4(15.1)$ & $25.2(13.8)$ & $<0.001$ \\
\hline Visible minorities, mean \% (SD) & $38.5(26.0)$ & $32.4(24.9)$ & $27.8(22.6)$ & $23.6(19.9)$ & $<0.001$ \\
\hline $\begin{array}{l}\text { Do not speak official language (English } \\
\text { or French) at home, mean \% (SD) }\end{array}$ & $39.4(22.1)$ & $34.5(21.1)$ & $31.0(19.6)$ & $27.7(17.3)$ & $<0.001$ \\
\hline Aboriginal identity, mean \% (SD) & $2.5(5.7)$ & $2.2(4.4)$ & $2.1(4.2)$ & $2.0(4.1)$ & $<0.001$ \\
\hline $\begin{array}{l}\text { Postsecondary education, mean \% } \\
\text { (SD) }\end{array}$ & $54.8(14.0)$ & $56.9(13.6)$ & $58.7(13.5)$ & $60.2(12.9)$ & $<0.001$ \\
\hline Employed, mean \% (SD) & $93.3(5.7)$ & $93.5(5.8)$ & $93.7(5.5)$ & $93.9(5.2)$ & $<0.001$ \\
\hline $\begin{array}{l}\text { Household total income, CDN\$, } \\
\text { median (SD) }\end{array}$ & 85434 (32 435) & 90779 (35 727) & 944486 (38 827) & 96986 (41 439) & $<0.001$ \\
\hline All cancer, $\mathrm{n}$ & 615 & 737 & 928 & 1159 & $<0.001$ \\
\hline Major cancer, $n$ & 264 & 381 & 470 & 604 & $<0.001$ \\
\hline Breast cancer, $\mathrm{n}$ & 83 & 125 & 127 & 183 & $<0.001$ \\
\hline Colorectal cancer, $\mathrm{n}$ & 57 & 68 & 91 & 101 & $<0.001$ \\
\hline Lung cancer, n & 30 & 44 & 57 & 61 & $<0.001$ \\
\hline Prostate cancer, $\mathrm{n}$ & 63 & 80 & 77 & 110 & $<0.001$ \\
\hline $\begin{array}{l}\text { Skin cancer, } \mathrm{n} \text { (non-melanoma/ } \\
\text { melanoma) }\end{array}$ & $31(5 / 26)$ & $64(15 / 49)$ & $118(17 / 101)$ & 149 (21/128) & $<0.001$ \\
\hline Other cancer, $\mathrm{n}$ & 351 & 356 & 458 & 555 & $<0.001$ \\
\hline
\end{tabular}

There were 2849 census dissemination areas.

BMI, body mass index.

for CDA-level SES covariates. Vitamin D quartile met the assumption of proportional hazards (ie, no significant interaction with time) in every model, however several covariates did not and were therefore modelled using time-dependent covariates in each model.

After adjusting for age, associations with any cancer, major cancer, breast cancer and skin cancer exceeded the threshold for Bonferroni significance (table 2; $p$ for trend $<0.00625$ ). Further adjustment for sex, BMI, mean daily hours of daylight during month of testing resulted in the association with breast cancer becoming nonsignificant at the Bonferroni threshold (table 2). Additional adjustment for CDA-level SES covariates resulted in only any cancer, major cancer and skin cancer remaining significant at the Bonferroni threshold. Importantly, the association with major cancer was no longer significant after removing cases of skin cancer ( $p$ for trend $=0.15$ ), confirming that this association was driven by the association with skin cancer, which was the strongest observed. Compared with the bottom quartile of serum 25-hydroxyvitamin $\mathrm{D}$, participants in the top quartile had a $2.56 \mathrm{X}$ greater risk of skin cancer after adjusting for covariates. Analysis by type of skin cancer yielded a similar association for non-melanoma, but the association for melanoma was not significant at either threshold of significance-perhaps due to a small number of melanomas in our study ( $\mathrm{n}=58$; results not shown).

We observed four nominally significant interactions between 25-hydroxyvitamin D quartile and CDA-level SES covariates on skin cancer risk (table 3). For an 
Table 2 Cox proportional hazard regression of serum 25-hydroxyvitamin D quartile and risk of cancer

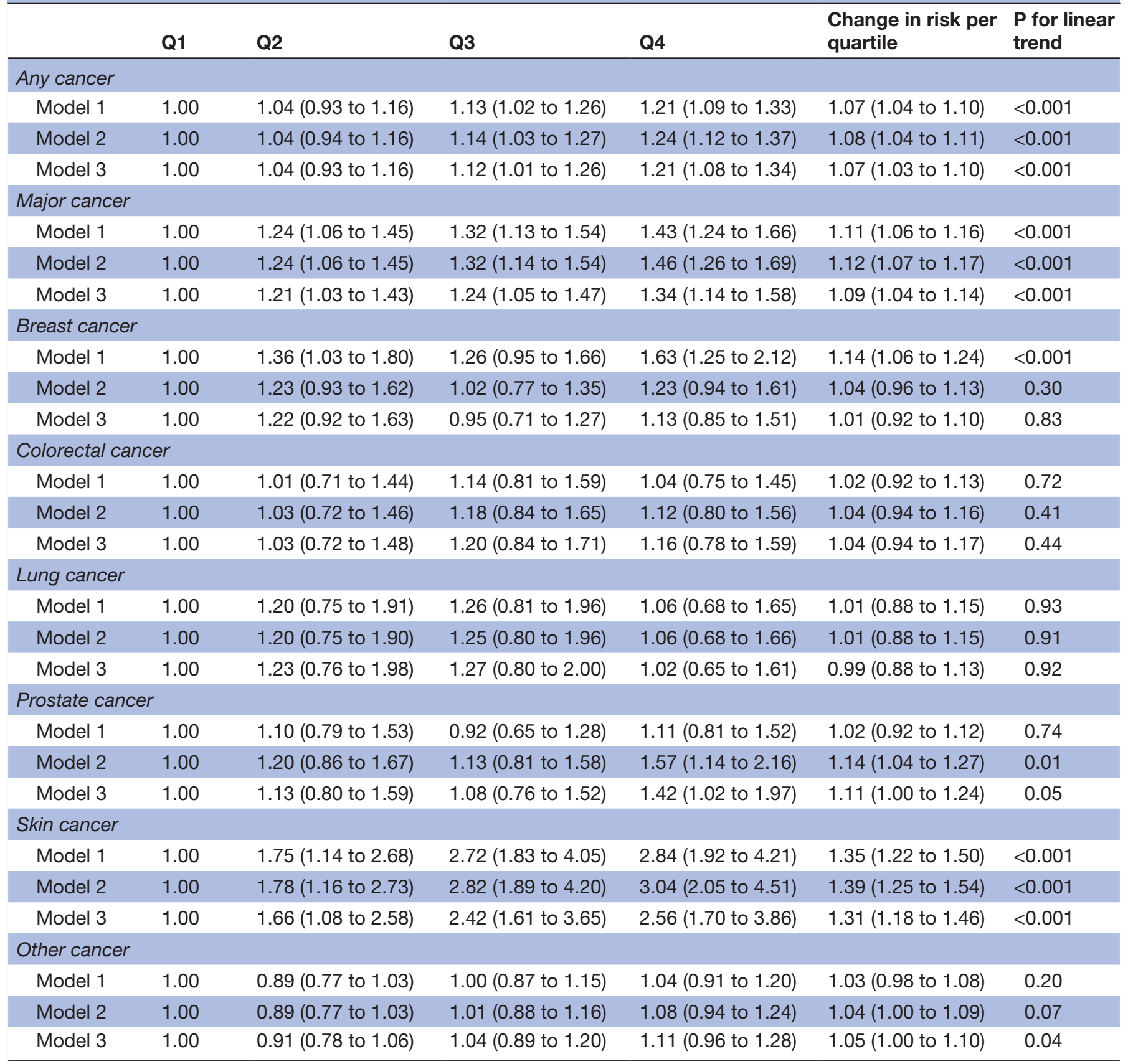

HR are indicated with $95 \%$ Cls in parenthesis.

Model 1, adjusted for age and log(time) interaction with age.

Model 2, model 1 additionally adjusted for sex, BMI, mean daylight hours during month of testing and log(time) interactions with sex, BMI and mean daylight hours during month of testing.

Model 3, model 2 additionally adjusted for CDA-level proportion of Canadian citizens, recent immigrants, visible (non-white) minorities, those indicating Aboriginal identity, those not speaking official languages (English or French) at home, those with postsecondary education, those currently employed, the CDA median household income and log(time) interactions with CDA-level proportion of Canadian citizens, those indicating Aboriginal identity and those with postsecondary education.

$\mathrm{BMI}$, body mass index; CDA, census dissemination area.

increase in the CDA-level proportion of non-citizens, recent immigrants, visible (non-white) minorities and those not speaking official languages (English or French) at home, the individual-level association between 25-hydroxyvitamin D and skin cancer risk was stronger.
Removal of 11154 participants with 25-hydroxyvitamin D concentrations of at least $100 \mathrm{nmol} / \mathrm{L}$ deleted large numbers of cancer cases from the fourth quartile of serum 25-hydroxyvitamin vitamin D (any cancer: $-66 \%$, major cancer: $-66 \%$, breast cancer: $-59 \%$, colorectal 
Table 3 Association of serum 25-hydroxyvitamin D quartile with risk of skin cancer stratified by median values of CDA covariates

\begin{tabular}{|c|c|c|c|c|c|c|}
\hline & Q1 & Q2 & Q3 & Q4 & $\begin{array}{l}\text { P for linear } \\
\text { trend }\end{array}$ & $\begin{array}{l}P \text { for } \\
\text { interaction }\end{array}$ \\
\hline \multicolumn{7}{|c|}{ Proportion of Canadian citizens } \\
\hline$\geq 92.7 \%$ & 1.00 & 1.86 (1.05 to 3.31$)$ & 2.33 (1.37 to 3.97$)$ & 2.21 (1.28 to 3.81$)$ & $<0.001$ & 0.03 \\
\hline$<92.7 \%$ & 1.00 & 1.36 (0.69 to 2.67$)$ & 2.55 (1.34 to 4.85$)$ & 3.16 (1.71 to 5.84$)$ & $<0.001$ & \\
\hline \multicolumn{7}{|c|}{ Proportion of recent immigrants } \\
\hline$\geq 26.7 \%$ & 1.00 & 1.55 (0.72 to 3.31$)$ & 2.99 (1.51 to 5.95$)$ & 3.24 (1.65 to 6.34$)$ & $<0.001$ & 0.04 \\
\hline$<26.7 \%$ & 1.00 & 1.66 (0.97 to 2.85$)$ & 2.08 (1.25 to 3.45$)$ & 2.18 (1.31 to 3.64$)$ & $<0.001$ & \\
\hline \multicolumn{7}{|c|}{ Proportion of visible (non-white) minorities } \\
\hline$\geq 24.3 \%$ & 1.00 & 1.99 (0.95 to 4.15$)$ & $2.83(1.39$ to 5.73$)$ & 3.06 (1.53 to 6.09$)$ & $<0.001$ & 0.03 \\
\hline$<24.3 \%$ & 1.00 & 1.47 (0.86 to 2.54$)$ & 2.16 (1.31 to 3.56$)$ & 2.26 (1.37 to 3.73$)$ & $<0.001$ & \\
\hline \multicolumn{7}{|c|}{ Proportion of non-official language (English or French) speakers at home } \\
\hline$\geq 29.2 \%$ & 1.00 & 1.39 (0.67 to 2.90$)$ & 2.58 (1.31 to 5.07$)$ & 2.75 (1.41 to 5.35$)$ & $<0.001$ & 0.02 \\
\hline$<29.2 \%$ & 1.00 & 1.79 (1.03 to 3.10$)$ & 2.33 (1.40 to 3.90$)$ & 2.47 (1.47 to 4.14$)$ & $<0.001$ & \\
\hline
\end{tabular}

HRs are indicated with $95 \% \mathrm{Cls}$ in parenthesis.

All models are adjusted for age, sex, BMI, mean daylight hours during month of testing, CDA-level proportions of Canadian citizens, recent immigrants, visible (non-white) minorities, those not speaking official languages (English or French) at home, those indicating Aboriginal identity, those with postsecondary education, those currently employed and the CDA median household income unless stratified by that variable. They were also adjusted for log(time) interactions with CDA-level proportion of Canadian citizens, those indicating Aboriginal identity and those with postsecondary education. Only nominally significant interactions are shown.

$\mathrm{BMI}$, body mass index; CDA, census dissemination area.

cancer: $-70 \%$, lung cancer: $-74 \%$, prostate cancer: $-67 \%$, skin cancer: $-66 \%$, other cancer: $-66 \%$ ). While this did not change our overall findings, associations with any and major cancer were no longer significant at the Bonferroni threshold, and associations with prostate and other cancer were no longer borderline-significant or significant at the nominal threshold. Only the association with skin cancer remained significant at the Bonferroni threshold, and was in fact strengthened (HR per quartile change 1.33; $95 \%$ CI 1.17 to 1.50 ; $\mathrm{p}$ for trend $<0.001)$. Repeating the sensitivity analysis using serum 25-hydroxyvitamin D as a continuous variable yielded identical results.

\section{DISCUSSION}

In a community population of patients under investigation for cardiovascular disease, higher serum 25-hydroxyvitamin D was associated with an increased risk of developing skin cancer. This association became stronger as the CDA-level proportion of non-citizens, recent immigrants, visible (non-white) minorities and those not speaking official (English or French) languages at home increased. Associations with prostate and other cancers were weak and may have been due to chance.

Vitamin D (vitamin $\mathrm{D}_{2}+$ vitamin $\mathrm{D}_{3}$ ), which can be synthesised in the skin (vitamin $\mathrm{D}_{3}$ ) from 7-dehydrocholesterol and ultraviolet (UV) radiation or obtained through diet (vitamin $\mathrm{D}_{2}$ or $\mathrm{D}_{3}$ ), undergoes two hydroxylations to the biologically active 1,25-dihydroxyvitamin $\mathrm{D}\left(\mathrm{D}_{2}+\mathrm{D}_{3}\right.$; calcitriol). ${ }^{23} 1,25$-Dihydroxyvitamin $\mathrm{D}$ binds to vitamin $\mathrm{D}$ receptors on target tissues, causing increased update of calcium and phosphate from the small intestine, and increased calcium mobilisation from bone via enhanced osteoclast activity. ${ }^{23}$ However, 25-hydroxyvitamin D $\left(\mathrm{D}_{2}+\mathrm{D}_{3}\right)$ reflects an individual's true vitamin $\mathrm{D}$ status from both endogenous and exogenous sources because of its long half-life (approximately 2-3 weeks vs 4-6hours for 1,25-dihydroxyvitamin D), its high concentration (1000 times greater than 1,25-dihydroxyvitamin D) and its resistance to metabolic changes. ${ }^{23}$

In animal experiments, 1,25 dihydroxyvitamin $\mathrm{D}$ has important cellular effects that may decrease the risk of cancer or slow its progression. ${ }^{12}$ These have been cited as evidence that associations between serum 25-hydroxyvitamin D and cancer risk identified in epidemiological studies represent causal relationships. However, epidemiological studies are susceptible to unmeasured or residual confounding by factors associated with vitamin $\mathrm{D}$ deficiency and increased cancer risk (eg, adiposity, low SES). They are also susceptible to reverse causality, particularly because low serum 25-hydroxyvitamin $\mathrm{D}$ may in part be a marker of ill health. ${ }^{24}{ }^{25}$ This could cause individuals with subclinical cancer or other conditions to become vitamin $\mathrm{D}$ deficient. As genetic variants that modestly reduce 25-hydroxyvitamin $\mathrm{D}$ are, for the most part, not associated with an increased risk of cancer in Mendelian randomisation studies, ${ }^{26-28}$ this tends to support this hypothesis. However, in randomised controlled trials, vitamin D supplementation slightly reduces cancer mortality. ${ }^{29}{ }^{30}$ For example in the Vitamin D and Omega-3 Trial (VITAL), 2000 IU/day supplementation 
of vitamin $\mathrm{D}_{3}$ significantly reduced the risk of metastatic or fatal cancer compared with placebo, and this effect was stronger among individuals who had a normal BMI (ie, $\left.<25 \mathrm{~kg} / \mathrm{m}^{2}\right) .{ }^{31}$ Taken together, while the relationship between vitamin $\mathrm{D}$ status and cancer incidence may in part be due to confounding and reverse causality, vitamin D status may be causally related to mortality risk from cancer.

There is a well-established relationship between vitamin D status and sun exposure. ${ }^{32}$ For example, serum 25-hydroxyvitamin D concentration may rise above $100 \mathrm{nmol} / \mathrm{L}$ among individuals who perform extended outdoor activity in the central USA. ${ }^{33}$ However, this concentration is difficult to achieve without supplementation in locations where daylight hours are shorter (eg, at higher latitude) and sunlight is weaker (eg, at lower elevation). ${ }^{22}$ Sun exposure is also the most important risk factor for melanoma and non-melanoma skin cancerparticularly among individuals with a light skin tone. ${ }^{34}$ This is because UV radiation in sunlight induces the synthesis of vitamin D in skin, and damages its DNA without adequate protection by melanin. ${ }^{35}$ As expected, higher serum 25-hydroxyvitamin D concentration was associated with a higher risk of skin cancer in a recent meta-analyses of prospective cohort studies. ${ }^{36}$ And while results from Mendelian randomisation studies suggest that this is not a causal relationship, ${ }^{37} 38$ serum 25-hydroxyvitamin D concentration may still be useful as a skin cancer risk marker because its concentration is related to sun exposure.

In our study, we found a positive association between serum 25-hydroxyvitamin D and risk of skin cancer, which was consistent over time but stronger among individuals who resided in CDAs with a higher proportion of noncitizens, recent immigrants, visible minorities and those who did not speak an official language at home. This may be because individuals living in these communities are less likely to take vitamin D supplements, ${ }^{39}{ }^{40}$ which would make their serum 25-hydroxyvitamin D concentration more representative of sun exposure than supplementation-resulting in a stronger overall association with skin cancer risk. Interestingly, removal of individuals with $25-\mathrm{OH}$ vitamin D concentrations of $100 \mathrm{nmol} / \mathrm{L}$ or greater strengthened the association with skin cancerwhich suggests we may have indeed removed individuals who were more likely to be taking vitamin $\mathrm{D}$ supplements. In a study of non-lactating women, daily oral supplementation of $5000 \mathrm{IU} /$ day for 1 month raised serum 25-hydroxyvitamin $\mathrm{D}$ above $100 \mathrm{nmol} / \mathrm{L}^{41}$

This study has some strengths. First, we used available secondary data to assemble a large retrospective cohort of community patients while making several restrictions and exclusions to minimise bias. Second, while this population included only patients who received an ECG, any patients who had a 25-hydroxyvitamin D measurement were eligible for inclusion. During the testing period, our laboratories experienced a very high volume of serum 25-hydroxyvitamin D testing-likely because of substantial interest in vitamin $\mathrm{D}$ at the time. Third, we adjusted for several potentially important confounders, including mean daylight hours during month of testing, BMI and community-level measures of SES and examined variation in the association between serum 25-hydroxyvitamin D and cancer risk according to them.

This study also has some limitations. First, as it was based on secondary data, we had a limited number of variables and no control over when they were measured. Importantly, we could not tell if patients had taken vitamin D supplements. Supplementation elevates serum 25-hydroxyvitamin $\mathrm{D}$ in individuals who are vitamin D deficient, including those who are deficient because of low sun exposure and who are therefore at low risk for skin cancer. Including these individuals in our study would weaken the strong and biologically plausible relationship we and others have observed between sun exposure, serum 25-hydroxyvitamin D concentration and skin cancer risk. As such, we may have underestimated the true association in our study-especially since we observed variation in this association according to community-level factors related to supplement use, and a strengthening of this association after removing patients with a serum 25-hydroxyvitamin $\mathrm{D}$ concentration of $100 \mathrm{nmol} / \mathrm{L}$ or greater. We also included only a single measure of serum 25-hydroxyvitamin $\mathrm{D}$ for patients in our study. However, even a single measure may be useful in representing usual status due to its moderate intraindividual variation (Spearman's $\mathrm{R}$, intraclass correlation coefficient $=\sim 0.6$ ) over similar time periods as our study. ${ }^{42}$ Using the first measure may also better represent historic vitamin $\mathrm{D}$ status which is more likely to be associated with cancer risk than recent changes from supplementation in response to a diagnosis of deficiency. Interestingly, we found no change in our associations according to elapsed time between 25-hydroxyvitamin D testing and cancer diagnosis-which suggests our single measure may have adequately estimated usual vitamin D status. Second, as our study was observational, we could not determine whether the 25-hydroxyvitamin D-cancer relationship was causal. However, this was not an objective of our study nor was it even achievable. Third, while we did not include participants without a BMI and ECG, we felt obtaining BMI was critical for reducing bias-even if it was based on self-report. We keep only participants who had BMI measured within a short period of time ( \pm 3 months) from 25-hydroxyvitamin D measurement to maximise its relevance to 25-hydroxyvitamin D concentration. However, because ECGs are used to identify the presence of cardiovascular disease, our population may be at an elevated risk for both cardiovascular disease and cancer because many of the risk factors for cardiovascular disease are also risk factors for cancer (eg, poor diet) ${ }^{43}$

\section{CONCLUSION}

Higher vitamin D status was associated with a greater risk of skin cancer in a large community population under 
investigation for cardiovascular disease. This association is likely due to sun exposure and may be modified by community variation in supplementation rates.

Twitter Lawrence de Koning @Idekoning

Contributors LdeK, JY and CN designed the study. LdeK acquired the data. JY, YD and LdeK conducted the statistical analysis. LdeK, JY, YD and CN interpreted the data. LdeK and JY drafted the manuscript. JY, YD, CN and LdeK critically revised and approved the final version of the manuscript. LdeK supervised the project, obtained funding and acts as the guarantor.

Funding This work was partially supported by funding from the MSI foundation of Alberta (grant \#871) to LdeK, and summer studentship awards to JY from Calgary Laboratory Services and the University of Calgary.

Disclaimer All funding sources had no role in this work.

Competing interests None declared.

Patient and public involvement Patients and/or the public were not involved in the design, or conduct, or reporting, or dissemination plans of this research.

Patient consent for publication Not applicable.

Ethics approval This study was approved by the University of Calgary Conjoint Health Review Ethics Board (Ethics ID 25065). Research in this article was carried out in accordance with The Code of Ethics of the World Medical Association (Declaration of Helsinki).

Provenance and peer review Not commissioned; externally peer reviewed.

Data availability statement Data are available on reasonable request.

Open access This is an open access article distributed in accordance with the Creative Commons Attribution Non Commercial (CC BY-NC 4.0) license, which permits others to distribute, remix, adapt, build upon this work non-commercially, and license their derivative works on different terms, provided the original work is properly cited, appropriate credit is given, any changes made indicated, and the use is non-commercial. See: http://creativecommons.org/licenses/by-nc/4.0/.

ORCID iD

Lawrence de Koning http://orcid.org/0000-0003-2877-4377

\section{REFERENCES}

1 Institute of Medicine. Dietary Reference Intakes for Calcium and Vitamin D. Washington, DC, USA: The National Academies Press, 2011.

2 Holick MF, Binkley NC, Bischoff-Ferrari HA, et al. Evaluation, treatment, and prevention of vitamin $D$ deficiency: an endocrine Society clinical practice guideline. J Clin Endocrinol Metab 2011;96:1911-30.

3 Fraser WD. Chapter 64: Bone and Mineral Metabolism. In: Rifai N, ed. Tietz textbook of clinical chemistry and molecular diagnostics. 6th ed. St. Louis, MO.: Elsevier, 2018: 1422-91.

4 Wacker M, Holick MF. Sunlight and vitamin D: a global perspective for health. Dermatoendocrinol 2013;5:51-108.

5 Janz T, Pearson C. Vitamin D blood levels of Canadians. Ottawa, Canada.: Statistics Canada, 2013.

6 Yin L, Ordóñez-Mena JM, Chen T, et al. Circulating 25-hydroxyvitamin D serum concentration and total cancer incidence and mortality: a systematic review and meta-analysis. Prev Med 2013;57:753-64.

7 Ma Y, Zhang P, Wang F, et al. Association between vitamin D and risk of colorectal cancer: a systematic review of prospective studies. $J$ Clin Oncol 2011;29:3775-82.

8 Dunn JA, Jefferson K, MacDonald D, et al. Low serum 25-hydroxyvitamin $D$ is associated with increased bladder cancer risk: a systematic review and evidence of a potential mechanism. $J$ Steroid Biochem Mol Biol 2019;188:134-40.

9 Mäkitie A, Tuokkola I, Laurell G, et al. Vitamin D in head and neck cancer: a systematic review. Curr Oncol Rep 2020;23:5.

10 Zhang $Y$, Jiang X, Li X, et al. Serum vitamin D levels and risk of liver cancer: a systematic review and dose-response meta-analysis of cohort studies. Nutr Cancer 2021;73:1-9.

11 Chowdhury R, Kunutsor S, Vitezova A, et al. Vitamin D and risk of cause specific death: systematic review and meta-analysis of observational cohort and randomised intervention studies. BMJ 2014;348:g1903.
12 Bandera Merchan B, Morcillo S, Martin-Nuñez G, et al. The role of vitamin $D$ and VDR in carcinogenesis: through epidemiology and basic sciences. J Steroid Biochem Mol Biol 2017;167:203-18.

13 Vanlint S. Vitamin D and obesity. Nutrients 2013;5:949-56.

14 Bhaskaran K, Douglas I, Forbes H, et al. Body-Mass index and risk of 22 specific cancers: a population-based cohort study of $5 \cdot 24$ million UK adults. Lancet 2014;384:755-65.

15 de Koning L, Henne D, Woods P, et al. Sociodemographic correlates of 25-hydroxyvitamin D test utilization in Calgary, Alberta. BMC Health Serv Res 2014;14:339.

16 Merletti F, Galassi C, Spadea T. The socioeconomic determinants of cancer. Environ Health 2011;10 Suppl 1:S7

17 Bikos K. Calgary, Alberta, Canada - Sunrise, sunset, and Daylength, 2021. Available: https://www.timeanddate.com/sun/canada/calgary [Accessed 23 Jul 2021].

18 de Koning L, Al-Turkmani MR, Berg AH, et al. Variation in clinical vitamin D status by DiaSorin liaison and LC-MS/MS in the presence of elevated 25-OH vitamin D2. Clin Chim Acta 2013;415:54-8.

19 Canadian Cancer Society. Cancer statistics at a glance, 2021. Available: https://www.cancer.ca/en/cancer-information/cancer-101/ cancer-statistics-at-a-glance/?region=on

20 International Agency for Research on Cancer. The cancer dictionary Lyon, France.: World health Organizatio, 2010. Available: https:// www-dep.iarc.fr/WHOdb/WHOdb.htm [Accessed 5 Mar 2021].

21 Bradburn MJ, Clark TG, Love SB, et al. Survival analysis Part III: multivariate data analysis -- choosing a model and assessing its adequacy and fit. Br J Cancer 2003;89:605-11.

22 Sowah D, Fan X, Dennett L, et al. Vitamin D levels and deficiency with different occupations: a systematic review. BMC Public Health 2017; $17: 519$.

23 Fraser WD. Bone and Mineral Metabolism. In: Rifai N, Horvath AR, Wittwer CT, edseds. Tietz Textboook of clinical chemistry and molecular diagnostics. 6th. St. Louis, MO, USA: Elsevier, 2018: 1422-91.

24 Autier P, Boniol M, Pizot C, et al. Vitamin D status and ill health: a systematic review. Lancet Diabetes Endocrinol 2014;2:76-89.

25 Autier P, Mullie P, Macacu A, et al. Effect of vitamin D supplementation on non-skeletal disorders: a systematic review of meta-analyses and randomised trials. Lancet Diabetes Endocrinol 2017;5:986-1004.

26 Dimitrakopoulou VI, Tsilidis KK, Haycock PC, et al. Circulating vitamin $\mathrm{D}$ concentration and risk of seven cancers: Mendelian randomisation study. BMJ 2017;359:j4761.

27 Aspelund T, Grübler MR, Smith AV, et al. Effect of genetically low 25-hydroxyvitamin D on mortality risk: Mendelian randomization analysis in 3 large European cohorts. Nutrients 2019;11. doi:10.3390/ nu11010074. [Epub ahead of print: 02 Jan 2019].

28 Ong J-S, Gharahkhani P, An J. Vitamin D and overall cancer risk and cancer mortality: a Mendelian randomization study. Hum Mol Genet 2018;27:4315-22.

29 Keum N, Lee DH, Greenwood DC, et al. Vitamin D supplementation and total cancer incidence and mortality: a meta-analysis of randomized controlled trials. Ann Oncol 2019;30:733-43.

30 Zhang Y, Fang F, Tang J, et al. Association between vitamin D supplementation and mortality: systematic review and meta-analysis. BMJ 2019;366:14673.:14673.

31 Chandler PD, Chen WY, Ajala ON, et al. Effect of vitamin D3 supplements on development of advanced cancer: a secondary analysis of the vital randomized clinical trial. JAMA Netw Open 2020;3:e2025850.

32 Jager N, Schöpe J, Wagenpfeil S, et al. The Impact of UV-dose, Body Surface Area Exposed and Other Factors on Cutaneous Vitamin D Synthesis Measured as Serum 25(OH)D Concentration: Systematic Review and Meta-analysis. Anticancer Res 2018;38:1165-71.

33 Barger-Lux MJ, Heaney RP. Effects of above average summer sun exposure on serum 25-hydroxyvitamin D and calcium absorption. $J$ Clin Endocrinol Metab 2002;87:4952-6.

34 American Cancer Society. Cancer Facts \& Figures 2021. Atlanta, Georgia, USA; 2021.

35 Institute of Medicine. Dietary Reference Intakes for Calcium and Vitamin D. Washington, DC, USA.: The National Academies Press, 2011.

36 Mahamat-Saleh Y, Aune D, Schlesinger S. 25-Hydroxyvitamin D status, vitamin $D$ intake, and skin cancer risk: a systematic review and dose-response meta-analysis of prospective studies. Sci Rep 2020;10:13151

37 Winsløw UC, Nordestgaard BG, Afzal S. High plasma 25-hydroxyvitamin D and high risk of nonmelanoma skin cancer: a Mendelian randomization study of 97849 individuals. Br J Dermatol 2018;178:1388-95. 
38 Liyanage UE, Law MH, Barrett $\mathrm{JH}$. Is there a causal relationship between vitamin $\mathrm{D}$ and melanoma risk? A Mendelian randomization study. Br J Dermatol 2020;182:97-103.

39 Gordon NP, Caan BJ, Asgari MM. Variation in vitamin D supplementation among adults in a multi-race/ethnic health plan population, 2008. Nutr J 2012;11:104.

40 Moffat T, Sellen D, Wilson W, et al. Comparison of infant vitamin D supplement use among Canadian-born, immigrant, and refugee mothers. J Transcult Nurs 2015;26:261-9.
41 Meekins ME, Oberhelman SS, Lee BR, et al. Pharmacokinetics of daily versus monthly vitamin D3 supplementation in non-lactating women. Eur J Clin Nutr 2014;68:632-4.

42 Meng JE, Hovey KM, Wactawski-Wende J, et al. Intraindividual variation in plasma 25 -hydroxyvitamin D measures 5 years apart among postmenopausal women. Cancer Epidemiol Biomarkers Prev 2012;21:916-24.

43 Lau ES, Paniagua SM, Liu E, et al. Cardiovascular risk factors are associated with future cancer. JACC CardioOncol 2021;3:48-58. 